\title{
A ONTOLOGIA DA DIVERSIDADE HUMANA (ABORTADA) E A IDEOLOGIA DA DIVERSIDADE CULTURAL ${ }^{1}$
}

lael de Souza²

Resumo: Demonstrar a diferença substancial entre diversidade humana e diversidade cultural se faz essencial e imprescindível atualmente, ainda mais quando o irracionalismo pós-moderno avança e ameaça de contágio todo 0 universo da produção científica, desontologizando o real e o próprio ser social, desterrando a historicidade dos fatos e fenômenos sociais, a causalidade, a teleologia e as mediações inelimináveis entre as instâncias que perfazem a totalidade social (universal, particular e singular). Afirmar e repor a necessidade de contra-hegemonia, pensando crítica, científica e historicamente a realidade em seu movimento processual dialético, se faz uma tarefa premente a fim de fortalecer o projeto político-social de "revolução política com alma social" em prol da emancipação humana.

Palavras-chave: Diversidade humana. Diversidade cultural. Emancipação humana.

\begin{abstract}
Demonstrating the substantial difference between human diversity and cultural diversity is essential and imperative nowadays, especially when postmodern irrationalism advances and threatens to infect the whole scientific production universe, by disontologyzing actuality and the social being himself, wiping out the annals of social facts and phenomena, causality, teleology and the mediations bound up with the instances which fill in (universal, private and singular) social entirety. Affirming and refocusing the anti-hegemonic need, by reflecting critically, scientifically and historically on reality on its dialectical procedural course, is an immediate task in order to strengthen the sociopolitical project on "political revolution hinged on its social soul" for the sake of human emancipation.
\end{abstract}

Keywords: Human diversity. Cultural diversity. Human emancipation.

\section{Introdução}

Um novo modismo penetra e se alastra pela produção científicoacadêmica: a onda culturalista. Linguagem, discurso e cultura, e a ênfase na diferença, tornam-se o mote daqueles que se intitulam pós-modernistas, e todos

\footnotetext{
${ }_{1}^{1}$ DOI: https://doi.org/10.22409/tn.15i27.p9633

${ }^{2}$ Professora da Universidade Federal do Piauí (UFPI), Dpto de Educação. Mestre em Ciências Sociais pela UNESP - Marília. Doutoranda do curso de Educação da UNICAMP - SP. E-mail: iaeldeo@gmail.com.
}

TrabalhoNecessario - www.uff.br/trabalhonecessario; Ano 15, № 27/2017 
aqueles que se contrapõem são, de antemão, taxados de totalitários, dogmáticos, inflexíveis, deterministas e economicistas.

É necessário reconstituir - ainda que sumariamente, devido à limitação de espaço para esse artigo - a historicidade dos fatos, a fim de que possamos compreender o contexto histórico-social que propicia o surgimento da pósmodernidade e dos pós-modernos e porque são tão incisivos e peremptórios no ataque às metanarrativas, à categoria de totalidade social, ao humanismo, ao projeto de emancipação humana e demais categorias, conceitos (classe social, por exemplo) e projetos universalistas. Essa será uma de nossas tarefas.

Essa contextualização propiciará as bases para a compreensão da análise e reflexão que nos propomos desenvolver, pois possibilitará a distinção substancial entre diversidade humana e diversidade cultural, uma vez que a primeira remete ao processo de ontologização do ser social e sua complexificação sociabilizatória mediante o desenvolvimento das forças produtivas, da base técnico-material da produção e das condições materiais e espirituais de existência e reprodução social, então abortado e degradado pelo capital, como será demonstrado. Já a segunda, corresponde à "diversidade possível" dentro das limitadas condições histórico-sociais impostas pelas relações sociais e de produção capitalistas, pautadas na propriedade privada, na desigualdade social (de condições de desenvolvimento e realização humana) e na exploração do homem pelo homem, legitimada pela relação contratual, de mercado, legalizada pelo Estado de Direito.

Também procuraremos demonstrar como ocorre o processo de desontologização do real, da história e do ser social, então substituído pelo processo de ideologização cultural, contribuindo para o aprisionamento das consciências, que se reificam através do artificialismo das relações sociais mercantilizadas, tornando cada vez mais difícil a superação do estranhamento e da alienação humanas.

Esperamos, assim, contribuir para fortalecer a perspectiva do trabalho contra o capital, ou seja, a contra-hegemonia, num momento onde, como bem frisou Eric Hobsbawm, o capital se vinga do trabalho (política-econômica neoliberal). Mais do que em qualquer outro momento e época da história, principalmente quando proclamam o "fim da história", a "morte do sujeito", o "fim das ideologias", do "universalismo", etc., o momento e época atual exigem que 
recoloquemos, reafirmemos e defendamos, de modo fundamentado e historicamente, a "revolução política com alma social", como ressalvava Marx, e confrontemos, lúcida e racionalmente, os intelectuais orgânicos do capital.

\title{
Pós-modernismo: a aparência crítica de uma visão essencialmente não- crítica
}

\begin{abstract}
Se, diante das evidências da insuprimível atividade sensível dos homens, o conhecimento verdadeiro é pensado como inexistente, isto é uma abstração elaborada de um ponto de vista absurdo, correspondente ao egoísmo. E o que é egoísmo, se não o indivíduo posto em isolamento, produto de uma dada época histórica, cuja lógica específica da individuação consiste em separar e contrapor os indivíduos, já em si fragmentados? Negar ou fazer abstração da realidade e do conhecimento pode ser e, de fato, tem sido a componente ideal e a justificativa conformista alienação e estranhamento do homem, perda e contraposição do homem a si mesmo, identificados à natureza humana - da índole ferina da individuação produzida por uma sociabilidade cuja negação do homem é, em essência, sua única forma de o entificar. (CHASIN, 1995, p. 403)
\end{abstract}

A sentença de Chasin em epígrafe descreve a essência do significado da pós-modernidade, que tem como marco a II Guerra Mundial e a extensão do Estado de Bem-Estar social - a experiência norte-americana keynesiana - para a maioria dos países europeus, alimentando a necessária acumulação capitalista que, ao atingir o auge do seu patamar, nas décadas de 50 e 60 do século XX, culminaria com uma crise estrutural do capital sem precedentes, impondo, como saída, sua reestruturação metabólica a partir da década de 1970, que se consolida e hegemoniza globalmente nas décadas de 1980 e 1990, acarretando o processo de concentração e centralização do capital e a fusão do capital comercial, industrial e financeiro.

A prosperidade e desenvolvimento econômico-social das décadas de 50 e 60 do século XX na América do Norte e Europa provocaram uma euforia e a impressão de que o progresso - na verdade um surto de progresso - seria ad infinitum e que a humanidade havia chegado, afinal, ao "fim da história", ou seja, ao último e mais elevado estágio possível do desenvolvimento humano, materializado através da inimaginável potência e virtualidades alcançadas pelas forças produtivas - base técnico-material da produção, inovações e invenções técnico/tecnológicas/científicas. O melhor dos mundos possíveis parecia ter, 
enfim, se concretizado, apesar de muitas imperfeições e problemas sociais não terem sido equacionados, muito pelo contrário, foram agudizados, exigindo algum tipo de enfrentamento. De qualquer forma, a modernidade chegava ao fim - "fim da história", "fim das ideologias", "fim das metanarrativas", dos "essencialismos", "universalismos" e seus projetos emancipatórios, que passaram a ser entendidos como quimeras, ilusões, enfim, "coisas de criança". Entrava-se numa nova era: a da pós-modernidade.

Mas, afinal, o que foi a modernidade? Será que foi, era ou ainda é? Esse conceito engloba um longo processo e contexto histórico-social que compreende a crise de um modo de vida e o surgimento de um outro, a passagem do modo de produção feudal ao modo de produção capitalista, um processo revolucionário freado, interrompido, não levado às últimas consequências, degenerado em relação ao seu projeto político-social inicial de igualdade (de condições materiais e espirituais, ou seja, condições pressupostas, públicas - universais - para o desenvolvimento das individualidades - indivíduo, singularidade -, promovendo a diversidade, a multifacetariedade e enriquecimento humanos, comprovando a determinação reflexiva entre o social e o individual) para todos os homens. Portanto, abortado, frustrando a maioria da humanidade e beneficiando uma minoria, que privatiza a riqueza socialmente produzida, faz da exploração do homem pelo homem sua razão de ser e condição de enriquecer, fundamenta e legaliza, pelo Estado de Direito (racionalização e burocracia), a propriedade privada e a desigualdade social, legitimando-as ideologicamente através da máxima de uma natureza humana egoística, competitiva, individualista.

Sendo assim, devemos nos perguntar: qual é a visão de mundo (ideologia, em sentido amplo, como veremos mais adiante) que embasa o surgimento e estruturação do modo de vida capitalista (o mundo moderno, a modernidade)? Por que, a princípio, foi acreditada, sentida e vivida como revolucionária? Onde reside sua força, sua capacidade de persuasão e unificação das diferentes lutas empreendidas pelos diversos segmentos sociais (totalizar e unificar, conectando e mediando, as divergentes forças sociais)?

As respostas estão sintetizadas em conceitos (que são a síntese dialética de um período histórico-social) que os pós-modernos e pós-estruturalistas dentre os mais renomados pensadores atuais (após o niilismo de Nietzsche e o nazismo de Heidegger): Michel Foucault, Jean-François Lyotard, Jacques Derrida, 
Jacques Lacan -, combatem e negam, como: classe social, progresso, racionalidade, teleologia, humanismo, totalidade, unidade, dentre outros. Façamos os devidos esclarecimentos.

A transição do modo de produção feudal ao modo de produção capitalista até então embrionário e, por isso mesmo, sem contornos definidos que the qualificariam as tendências de desenvolvimento, o que possibilitou, num primeiro momento e por algumas décadas do processo revolucionário desencadeado, reunir e unir interesses e necessidades, em essência, antagônicos - resgatou e se reapropriou, readequando, de uma concepção de mundo cosmogônica e ontológica: a antiguidade clássica, cujas preocupações fundamentais giram em torno de descobrir a essência do ser das coisas, não apenas a explicação aparente dos fenômenos e fatos, mas seus fundamentos, levando à construção de uma visão de mundo integrado, demonstrando as causas primeiras e o encadeamento de causas e suas interdeterminações, mediações e determinações reflexivas entre o multiverso e o universo, entre singularidade, particularidade e universalidade do ser das coisas.

É assim que a Renascença e o lluminismo colocam a racionalidade humana, o antropocentrismo, no centro, e abre-se uma época de revoluções, tanto no âmbito científico, filosófico, quanto social, cultural, político e econômico. A razão potencializa a atualização das capacidades humanas, possibilitando o progresso e desenvolvimento da humanidade, o domínio da natureza pelo homem, que deixa de submeter-se a ela e servi-la, passando a dela se servir ao submetê-la e dobrá-la por sua engenhosidade criativa, racional e científica. É assim que a racionalidade funda o humanismo que, segundo Kenan Malik (1999), é constituído, em seu âmago, por duas "crenças definidoras":

Em primeiro lugar, os humanistas sustentam que os seres humanos, mesmo sendo partes integrantes da natureza e sujeitos as suas leis, ainda assim têm nela um status fundamental devido à sua capacidade sem igual, originada na razão e sociabilidade humanas, de superar as restrições que lhes são impostas por esta natureza. Em segundo, eles acreditam na unidade da humanidade, sustentando que todos os seres humanos possuem alguma coisa em comum, algo que é frequentemente chamado de 'natureza humana'. (MALIK, 1999, p. 133) 
Portanto, a racionalidade e o humanismo aparecem, no momento inicial do processo revolucionário, como forças integradoras, capazes de tecer a unidade na diversidade de interesses e necessidades em si antagônicos, pois só em determinado momento desse processo e período revolucionário ficará evidenciado que os interesses e necessidades do capital são irreconciliáveis e irremediáveis aos interesses do trabalho, que, por sua vez, é o único capaz de reunir e unir todas as lutas anti-opressão, anti-exploração, anti-discriminação, antiigualdade, anti-colonização, anti-imperialistas existentes, porque a única perspectiva que corresponde, de fato, aos interesses e necessidades do gênero humano.

Contudo, concomitantemente também se torna sua fraqueza, principalmente no decorrer do século XIX, quando a essa racionalidade é imputada uma teleologia, ou seja, que o progresso e o desenvolvimento são inerentes à evolução histórica, como se a história e a razão tivessem um projeto em si mesmas, servindo-se dos homens como instrumentos/meios para a realização de seu fim. Tal concepção ideocultural serve aos propósitos do capital e de suas personas, os capitalistas, já que assim justificam o mundo existente como o melhor e único mundo possível, de modo que a humanidade teria chegado ao seu estágio máximo, o teto da história, isto é, ao "fim da história".

Daí os pós-modernistas e pós-estruturalistas extrairão seu argumento antihumanista, anti-história, pois o século XX é entendido por eles como a consubstancialização maturada de todo aquele processo revolucionário (Renascença, lluminismo, Revolução Industrial, Revoluções Burguesas, Colonização, Lutas nacionalistas/anti-imperialistas, até chegar à "Globalização"), que acarretou as duas grandes guerras mundiais, sendo que a II Guerra foi o divisor de águas, gerando o produto máximo de toda uma era: o horror, o caos, a barbárie, a desumanização, o estilhaçamento e fragmentação do social, a frustração da promessa de felicidade, igualdade, solidariedade e coletividade humanas.

Aparentam, assim, serem os novos críticos de um mundo que chegou a sua estação final. Entretanto, como podem ser verdadeiramente críticos se desterram a condição de criticidade do pensamento que é, justamente, a historicidade e objetividade dos fatos e fenômenos sociais? Antes de adentrarmos nesse aspecto, é importante destacarmos algumas questões referentes à

TrabalhoNecessario - www.uff.br/trabalhonecessario; Ano 15, № 27/2017 
teleologia e ao essencialismo, pois são fundamentais para compreendermos a historicidade e objetividade de todas as coisas e, principalmente, do ser social.

Primeiro, a teleologia é inerente à atividade humana, ao ser social, e não à história, pois somente ele é capaz de prévia-ideação e de colocar em ação as causalidades, por poder, justamente, conhecê-las e, assim, manipulá-las para responder e satisfazer suas necessidades, ainda que não seja capaz de ter um controle e um conhecimento absoluto sobre todas as coisas, entreabrindo as margens para a atuação das casualidades, que jogam um papel especial no desenvolvimento humano, desafiando-o a encontrar novas respostas e soluções a problemas oriundos da satisfação das primeiras necessidades, como demonstra Vaisman (1989) ao explicitar algumas das reflexões teórico-práticas centrais da Ontologia do Ser Social, de Lukács.

Embora os pós-modernistas e pós-estruturalistas vejam no marxismo a estirpe mais particularmente virulenta de todos os "essencialismos", como destaca Wood (1999, p. 12 e 13), procurando, por isso, destruí-lo, desacreditando-o como um pensamento e práxis científica-política-filosófica séria, isso apenas demonstra a parcialidade e estreiteza da compreensão por eles construída, até porque a afirmação de Marx de que os homens fazem a história, mas não segundo sua vontade e sim sob condições e circunstâncias que dela independem, não significa, de maneira alguma, que seja impossível buscar conhecer e compreender a causalidade das mesmas, e isto porque, como também lembra Marx nas Teses sobre Feurbach, não podemos esquecer que embora sejam os homens "produto das circunstâncias e da educação e de que, portanto, homens modificados são produto de circunstâncias diferentes e de educação modificada, (...) as circunstâncias são modificadas precisamente pelos homens" (MARX, s/d, p. 208. Itálico nosso).

Em outras palavras, as circunstâncias e condições foram produzidas por alguma das gerações humanas em algum momento/período histórico determinado, sendo assim, é possível descobrir suas causas, analisar e avaliar como os homens agiram e reagiram a elas e assim, pelo conhecimento extraído desse desenvolvimento humano acumulado (patrimônio histórico-cultural), tomar a decisão mais adequada e apropriada para lidar com o(s) problema(s) presente(s), demonstrando que o que é comum aos homens e os une, a sua essência humana, "não é algo abstrato, interior a cada indivíduo isolado. É, em 
sua realidade, o conjunto das relações sociais" (MARX, s/d, p. 209), ou seja, não é razoável "pressupor um indivíduo humano abstrato, isolado", pois se assim fosse, "nele a essência humana só pode(ria) ser concebida como 'espécie', como generalidade interna, muda, que se limita a unir naturalmente os muitos indivíduos" (MARX, s/d, p. 209).

Portanto, a essência humana é historicamente determinada, "pertence, na realidade, a uma forma determinada de sociedade. Todos os mistérios que desviam a teoria para o misticismo encontram sua solução racional na prática humana e na compreensão desta prática" (MARX, s/d, p. 209 e 210. Itálico nosso). O ser social é um produto de si mesmo e de sua própria atividade na história, o que Lukcás denominou de "humanismo histórico". A única coisa que há de natural no ser social é seu corpo biofísico, elo inquebrantável que estabelece a relação dialética inexorável entre social e natural, entre a esfera orgânica e inorgânica da natureza que promovem a condição para o salto qualitativo que dá origem ao ser social e ao mundo humano.

No intuito de reiterar as afirmações tecidas sobre a questão do "essencialismo", cedemos espaço a Foster (1999, p. 204. Os colchetes são nossos):

(...) abandonar inteiramente a teoria e a explicação histórica para evitar 'essencialismo' e 'fundacionismo' é como jogar fora o bebê para manter limpa a água do banho. O próprio Marx forneceu [outra leitura] que se opunha ativamente à teoria (até mesmo à teoria 'marxista') que se arrogava o caráter de 'supra-histórica'. Nas Teses sobre Feurbach, apresentou o que continua a ser a mais exaustiva crítica ao que chamou de concepção 'essencialista' dos seres humanos e da natureza. Na verdade, o materialismo histórico já há muito se entrega a uma autocrítica, precisamente para expulsar todos os tipos de 'essencialismos', 'positivismos' e 'estruturalismos' que se intrometeram na filosofia da própria práxis - uma autocrítica que levou às percepções de teóricos como Gramsci, Sartre, Thompson e Raymond Williams. Esses pensadores distanciaram-se do 'marxismo oficial' positivista que nasceu da Segunda Internacional [1916] e, mais tarde, transformou-se em uma caricatura de si mesmo com o stalinismo. Ainda assim, permaneceram fiéis à crítica ao capitalismo e aos seus compromissos com as lutas dos oprimidos.

$\mathrm{Na}$ verdade, muitas das críticas dos pós-estruturalistas e pós-modernistas dirigem-se não ao pensamento e à filosofia da práxis de Marx e Engels, mas sim ao marxismo caricatural de alguns adeptos e seguidores (Kautsky é um bom

TrabalhoNecessario - www.uff.br/trabalhonecessario; Ano 15, №27/2017 
exemplo), repleto de tergiversações, mal-entendidos, bem como deturpações, simplificações e descontextualizações, algo percebido pelo próprio Engels em carta escrita a Bloch (ENGELS, s/d, p. 284-286).

Após essas breves, mas imprescindíveis ponderações, retomemos a questão da historicidade e objetividade dos fatos e fenômenos, algo que é negado pelos pós-modernistas e pós-estruturalistas, terminando por minar qualquer base racional para seus argumentos, resultando numa visão aparentemente crítica, quando, na verdade, é essencialmente não-crítica. Justifiquemos.

O primeiro aspecto a ressaltar é que a compreensão dos fatos e fenômenos sociais impõe a necessidade de buscar a causa (ou encadeamento de causas que invariavelmente têm um momento predominante, em última instância) que os fundamenta. Essa é a base da racionalidade humana. Ao negar justamente esse princípio racional, a causalidade, os pós-modernistas e pósestruturalistas tornam-se irracionais e essa irracionalidade alcança o extremo ao se desprenderem da história, que nada mais é do que a objetivação da ação humana (subjetividade objetivada), através de suas atividades socioprodutivas, em determinado contexto espaço-temporal (histórico).

Wood (1999, p. 14 e 15) tece considerações interessantes sobre esses aspectos. Vejamos:

a despeito de sua insistência em diferenças e especificidades que marcam épocas, a despeito de sua reivindicação de terem denunciado a historicidade de todos os valores e conhecimentos (ou precisamente devida a sua insistência na 'diferença' e na natureza fragmentada da realidade e do conhecimento humano), eles são impressionantemente insensíveis à história. (...) Estruturas e causas foram substituídas por fragmentos e contingências. Não há um sistema social (como, por exemplo, o sistema capitalista), com unidade sistêmica e 'leis dinâmicas' próprias; há apenas muitos e diferentes tipos de poder, opressão, identidade e 'discurso'. Temos que rejeitar não só as antigas 'histórias grandiosas', tal como os conceitos de progresso do lluminismo, mas também a noção de processo histórico e causalidade inteligíveis - e com elas, evidentemente, qualquer ideia de 'escrever a história'. Não há processos estruturados acessíveis ao conhecimento humano (ou, temos que supor, à ação humana); há somente diferenças anárquicas, separadas e inexplicáveis. Pela primeira vez, temos o que parece ser uma contradição em termos, uma teoria de mudança de época baseada em uma negação da história. 
Se não há causas, os fatos e fenômenos são isolados, assim como os indivíduos, verdadeiras mônadas, que apenas se associam em situações, circunstâncias e condições específicas para atingir seus objetivos individuais, também específicos, egoísticos. A associação dura enquanto se fizer necessário para a obtenção do que se deseja. Sendo assim, não há possibilidade de construir as conexões causais, as determinações reflexivas entre os fatos e fenômenos, pois a realidade é fragmentária e cada fragmento se esgota em si mesmo, de modo que podemos, tão somente, traduzi-los pela linguagem e construir discursos. Numa realidade estilhaçada, as ações devem ser pulverizadas, locais, daí a micropolítica e os micropoderes. Como conclui Wood (1999, p. 15),

Uma vez que não há sistemas ou história suscetíveis à análise
causal, não podemos chegar à origem dos muitos poderes que
nos oprimem. Nem tampouco, certamente, aspirar a algum tipo de
oposição unificada, de emancipação humana geral, ou mesmo a
uma contestação geral do capitalismo, como os socialistas
costumavam acreditar; o máximo que podemos esperar é um bom
número de resistências particulares e separadas.

Em suma, não há continuidade na descontinuidade, ou seja, na mudança, pois isso afirmaria a existência de uma estrutura, de uma totalidade social, em outras palavras, "aspectos comuns ou ligações comuns entre elementos heterogêneos e diversificados" (MALIK, 1999, p 124). Assim, os pósestruturalistas e pós-modernistas negam "quaisquer padrões ou processos unificadores entre os fragmentos diversificadores e em constante mudança que constituem a sociedade". (MALIK, 1999, p. 125)

$\mathrm{O}$ antiessencialismo e antitotalidade do pensamento pós-moderno e pósestrutural tem como característica marcante a indeterminação, encontrando "o sentido de formas sociais não em relações, mas em diferenças". (MALIK, 1999, p. 125) E o que dizer acerca da objetividade? Para os pós-estruturalistas e pósmodernistas ela é impensável, pois trata-se de explicações naturalistas, positivistas dos fatos e fenômenos sociais, procurando quantificá-los, buscando suas causas, suas permanências, o que é entendido por eles como um contrasenso, uma tentativa de naturalizar as diferenças que, justamente por representarem a diversidade, são anti-padrões, anti-sistemas. 
Malik (1999, p. 126. O negrito é nosso) faz uma observação muito pertinente a esse respeito, dizendo que

na pressa de liquidar de uma vez por todas com as teorias naturalistas (leia-se positivistas), o discurso pós-estruturalista (...) se levanta não apenas contra explicações naturalistas da sociedade, mas também contra quaisquer explicações causais ou, pelo menos, contra qualquer explicação que conceda prioridade a certas causas em detrimento de outras. Toda e qualquer ideia de determinação - mesmo no sentido nãoreducionista, tendo a ver com o que E. P. Thompson chama frequentemente de 'a lógica do processo', ou o que Raymond Williams (em Marxism and Literature [1978]) descreve como 'um processo complexo e inter-relacionado de limites e pressões' - é considerada como essencialista e, portanto, ilegítima.

A negação da objetividade é, para os pós-modernistas e pósestruturalistas, a afirmação da pluralidade do mundo, da realidade. Aqui, mais uma vez, denota-se a irracionalidade dos pós-modernos, pois como enfatiza Malik (CARR apud MALIK, 1999, p.130) através de citação de E. H. Carr:

Não se segue que, porque uma montanha parece assumir formas diferentes quando vista de ângulos diferentes, ela não tem objetivamente forma alguma ou tem uma infinidade de formas. Não se segue que, porque a interpretação desempenha um papel necessário na apuração dos fatos da história, e porque nenhuma interpretação é inteiramente objetiva, uma interpretação é tão boa como qualquer outra, e que os fatos da história não são acessíveis à interpretação objetiva.

Devemos partir do seguinte princípio: o mundo social, humano é um produto da transformação do mundo natural pelo ser social (surgido do salto qualitativo da esfera orgânica e inorgânica), e o mundo natural tem existência anterior ao mundo social, tendo, também, sua ontologia - como demonstram os gregos -, ou seja, o ser de todas as coisas tem base material, objetiva e é justamente essa materialidade e objetividade que permitiu ao ser social compreender a lógica imanente do ser das coisas, podendo manipulá-las e servirse delas, isto é, ir se apropriando e aproximando da forma mais adequada possível do real e da processualidade da realidade, construindo, assim, sua autodeterminação e autonomia relativa (porque sempre haverá uma dependência ineliminável do homem em relação à natureza, sua matéria-prima em todos os 
âmbitos, a começar pelo seu corpo biofísico) através da criação e produção do mundo social e da sua própria história.

Logo, a realidade existe, é objetiva e também cognoscível. Como bem frisou Lênin (1982, p. 103. O destaque em itálico é nosso):

a dialética materialista de Marx e de Engels contém certamente o relativismo, mas não se reduz a ele, isto é, reconhece a relatividade de todos os nossos conhecimentos, não no sentido da negação da verdade objetiva, mas no sentido da condicionalidade histórica dos limites da aproximação dos nossos conhecimentos em relação a esta verdade.

O fato de não conseguirmos conhecer tudo não nos impede de construir as múltiplas relações e determinações entre os fatos e fenômenos observados, ou seja, a totalidade social, rejeitada e denunciada pelos pós-modernistas e pósestruturalistas como sinônimo de totalitarismo. Porém, como alerta Malik (1999), "ao louvar a indeterminação e combater a ideia de totalidade, tudo isso em nome do antiessencialismo, abala sua própria capacidade de explicar historicamente fatos sociais", além do agravo de que "os fatos são arrancados de seu contexto vivo e compreendidos apenas em isolamento." (MALIK, 1999, p. 130 e 131)

A objetividade é a relação interativa existente entre diferentes seres efetivos. Com isso queremos dizer que "todo existente é objetivo e, portanto, faz parte de um complexo concreto e está em relações diversas e sempre determinadas e, portanto, históricas com outros entes". (DELLA FONTE, 2011, p. 31) De modo que, "a noção de objetividade implica a totalidade e a história. (...) a objetividade remete para a existência de objetos antepostos e na condição de inter-relacionamento" (DELLA FONTE, 2011, p. 31). A partir daí depreende-se que "todo objeto é, por sua essência, processualidade. Ser é totalidade, ser é historicidade. Cada elemento ganha existência a partir da totalidade de relações nas quais está mergulhado e que the constituem". (DELLA FONTE, 2011, p. 31)

A base da objetividade é a construção de relações, de mediações, de tessituras, algo que é negado pelos pós-modernos, como vimos. São elas que nos permitem uma aproximação a mais adequada e razoável possível da processualidade do real para uma ação o mais consciente e consequente possível. Decorre daí a maior ou menor eficácia das ações políticas e de todas as 
demais formas de intervenção sobre o social. Como assevera Della Fonte (2011, p. 32),

cada conhecimento tem sua peculiaridade, mas, ao mesmo tempo, tangencia e dialoga com outros modos de conhecer, em um processo de aproximação infinita com a realidade; processo infinito, nem por isso impossível de ocorrer. Desse modo, o conhecimento objetivo orienta-se pela perspectiva da totalidade, apreende e expressa, em um esforço aproximativo, as processualidades históricas que tecem o real.

Vemos, portanto, porque os pós-modernistas e pós-estruturalistas só aparentemente são críticos, uma vez que, como demonstrado, a condição essencial para a construção de análises críticas é rechaçada. Como denuncia Foster, "ao minar o próprio conceito de história - em qualquer sentido significativo, além do mero 'contar histórias' - esses teóricos roubaram a análise crítica do que sempre foi seu instrumento mais indispensável". (FOSTER, 1999, p. 203) Arrematando essa sentença, utiliza as palavras de E. P. Thompson para demonstrar o perigo dessas ideias a-históricas ou anti-históricas, pois com elas perde-se de vista "não 'a razão na história' em algum sentido abstrato, mas sim 'as razões do poder e as razões do dinheiro'”. (FOSTER, 1999, p. 203)

\section{A ontologia da diversidade humana (abortada) e a ideologia da diversidade cultural - considerações finais}

Dr. Reilly: Posso reconciliá-la com a condição humana, / a condição a que alguns, que foram tão longe quanto você, / conseguiram voltar. Eles podem lembrar-se / da visão que tiveram, mas deixam de se lamentar, / mantêm-se pela rotina comum, / aprendem a evitar as esperanças excessivas, / tornam-se tolerantes consigo mesmos e com os outros, / o que existe para dar e aceitar. Não se impacientam; / estão contentes com a manhã que separa / e com a noite que une, / dispostos à conversa casual ante a lareira; / duas pessoas que sabem que não se compreendem, / criando filhos que não compreendem, / e que nunca os compreenderão.

Célia: É isso o melhor da vida?

Reilly: É uma vida boa. (ELLIOT apud MÉSZÁROS, 1988, p. 231)

Vimos, de modo breve e condensado, um pouco do contexto históricosocial que contribuiu para o surgimento da pós-modernidade e do pós-

TrabalhoNecessario - www.uff.br/trabalhonecessario; Ano 15, № 27/2017 
estruturalismo, bem como suas principais detrações às características positivas do humanismo e da modernidade e às categorias e ideias que ambos engendram. Como observa Malik (1999, p. 141 e 142. O grifo é nosso),

\begin{abstract}
ocorreu na intelligentsia radical uma 'decepção geral com o curso da história recente, com a estratégia de partidos políticos que reivindicavam a herança de Marx e, principalmente, com o próprio proletariado. As classes que Engels havia louvado como as herdeiras da filosofia clássica não haviam conseguido agir conforme se esperava'. Alguns fatos ocorridos no pós-guerra consolidaram essas opiniões: a experiência do fracasso da revolta dos estudantes em maio de 1968; o colapso dos partidos stalinista e social-democrata na década de 1980; e o fim dos movimentos de libertação no Terceiro Mundo reforçaram a convicção de que a transformação social era uma quimera. (...) Para os teóricos do pós-guerra, o abismo entre crença e realidade poderia ser transposto não pela transformação da realidade, mas pela renúncia a tais crenças. Sem esperança na mudança social, pensadores pós-estruturalistas e pós-modernistas afirmaram, em vez disso, que igualdade e humanidade não tinham sentido e que a diferença e a diversidade deveriam ser a meta.
\end{abstract}

É assim que começamos a compreender os nexos causais e as circunstâncias objetivas que erigem a diferença e a diversidade cultural como solução explicativa para a maioria dos problemas contemporâneos - de raça, de sexo, de gênero, étnico, etc. -, ocorridos, na maioria das vezes, segundo seus defensores, pela falta de respeito ou negligência a elas. Também é aqui que principia a diferença substancial obliterada entre a ontologia da diversidade humana (abortada) e a ideologia da diversidade cultural.

Iniciemos esclarecendo o que significa ontologia da diversidade humana e porque encontra-se abortada. Por ontologia entendemos o tornar-se homem do homem, a autoconstrução histórico-social do ser social, que corresponde a um fazer-se acumulativo, um processo em constante devir, que proporciona a criação do indivíduo enquanto gênero humano através da práxis social unificadora/interdeterminada, que interliga todos os indivíduos sociais, colocandoos em relação, direta e indireta, através de complexas mediações e múltiplas determinações, evidenciadas somente por intermédio da análise concreta do processo concreto, porque em momentos e lugares diferentes, a mesma atividade pode assumir sentidos muito diferentes. 
O problema é que na organização social capitalista e devido à própria lógica perversa dessa relação social (capital), pautada na reprodução das desigualdades sociais fundada na propriedade privada dos bens e meios de produção, no trabalho assalariado, na divisão entre trabalho manual e intelectual, na sociedade de classes e no Estado capitalista, à maioria dos homens é impedido e inviabilizado o acesso ao desenvolvimento e benefícios trazidos pelo desenvolvimento das forças produtivas e pelo processo de complexificação da vida social ${ }^{2}$, de modo que não são capazes de comungar da própria humanidade, que Ihes é negada, obstaculizando seu processo de hominização e humanização, desfrutando de tudo aquilo produzido pelo gênero humano, material e espiritualmente falando.

É assim que a ontologia da diversidade humana, da riqueza social criada pelas atividades socioprodutivas e complexificação da vida social pela possibilidade objetivamente posta de desenvolvimento multilateral dos indivíduos sociais e suas potencialidades e capacidades humanas, é abortada. A produção da riqueza é, de fato, social, mas sua apropriação e usufruto são privados. Ao invés de uma apropriação, na plenitude possível e universal, da criatividade e engenhosidade humanas - o que potencializaria o desenvolvimento e objetivação de outras individualidades, contribuindo para sua realização e enriquecendo o patrimônio histórico-cultural de toda a humanidade, porque seria de livre acesso ao gênero humano -, temos, na sociabilidade do capital, um processo de desentificação do ser social, impedido de se sentir, fazer e realizar enquanto gênero humano, sendo incentivado, pela lógica do desenvolvimento desigual e combinado capitalista, a adotar, naturalizar e internalizar as máximas que retroalimentam tal lógica, ou seja, a competição, a concorrência, o individualismo e o egoísmo, que passam a ser acreditados como características inerentes à natureza humana, mais uma vez obliterando que a natureza humana é histórica, portanto, processual e concretamente construída pelo modo como o ser social organiza e articula as relações sociais e de produção ao longo de sua autoconstrução humana.

Por fim, na contramão do caráter crescentemente genérico da vida de cada um de nós, portanto, do fato de que estamos cada vez mais conectados e

\footnotetext{
${ }^{2}$ Para uma melhor compreensão sobre a relação indivíduo/gênero sugerimos o livro de Sérgio Lessa A Ontologia de Lukács, capítulo V, "A Categoria da Reprodução Social".
} 
dependentes uns dos outros e de que a vida de todos está presente na vida de cada um, está o isolacionismo estabelecido pela lógica das relações sociais e de produção capitalista, na sensação e no sentir-se só no meio da multidão, como diria Drumond, tornando os indivíduos sociais em mônadas assoladas pelo estado de angústia e solidão. Mészáros (1988), citando um poema de Elliot, aponta justamente esse sentimento de solidão como mediação potencial para transcender positivamente o atual estado de fetichização e alienação humanas, promovendo o reencontro dos indivíduos consigo mesmos e com sua humanidade genérica. Conforme as palavras da personagem Célia:

O que aconteceu me tornou consciente / de que sempre estive só. De que se está sempre só. / ... não que eu queira estar só, / mas todos estão sós - ou me parecem estar. / Fazem barulho, e acham que estão conversando; / Fazem caretas, e acham que estão se compreendendo mutuamente. / $\mathrm{E}$ eu tenho certeza de que não estão. (ELLIOT apud MÉSZÁROS, 1988, p. 230-231)

A personagem é capacitada de perceber o esquema da alienação, de cair em si e compreender que as relações humanas são estabelecidas e mantidas através não das pessoas humanas, mas sim pela mediação dos objetos e produtos da criação e atividade produtiva humana; uma relação entre coisas, onde os indivíduos figuram como meio para efetivar a troca e garantir a circulação das mercadorias, bem como a reprodução do sistema metabólico do capital e da sua acumulação ad infinitum.

Por isso, como nos alerta Lessa (2004, p. 5),

o isolamento do sofrimento de cada um é condição necessária para que tal sofrimento seja suportado cotidianamente como algo inevitável e, neste caso muito diretamente, tal isolamento cumpre uma função na manutenção da reprodução social regida pelo capital. Este isolamento solitário (...) é uma das características mais marcantes dos indivíduos que são formados neste mundo 'globalizado'.

Após esse sumário esclarecimento, começamos a compreender porque a solidariedade de classe, a coletividade e a própria humanidade estão desacreditadas, afinal, num mundo cada vez mais hedonista, individualista, competitivo, concorrencial, fragmentado e particularizado em diferenças e 
localismos, o que é estimulado é o isolamento e não a articulação totalizadora e mediata, produzida histórica e objetivamente pelos homens. Logo,

as ideias da classe dominante são, em cada época, as ideias dominantes, isto é, a classe que é a força material dominante da sociedade é, ao mesmo tempo, sua força espiritual dominante. A classe que tem à sua disposição os meios da produção material dispõe também dos meios da produção espiritual, de modo que a ela estão submetidos aproximadamente ao mesmo tempo os pensamentos daqueles aos quais faltam os meios da produção espiritual. As ideias dominantes não são nada mais do que a expressão ideal das relações materiais dominantes, são as relações materiais dominantes apreendidas como ideias. (MARX; ENGELS, 2007, p. 47)

A "expressão ideal das relações materiais dominantes" corresponde à expressão ideológica dessas mesmas relações. De modo que a realidade é ideologizada, servindo aos propósitos de uma determinada classe, e não aos de outra, influenciando na escolha entre alternativas postas aos indivíduos sociais, ao mesmo tempo que cria a ilusão de possibilidade de liberdade de escolha e de liberdade individual, pois, na verdade, sua objetivação pressupõe o que the é negado e imanente: a criação de condições públicas, isto é, postas igualmente para todos, a fim de que cada um possa suprir as necessidades de sua individualidade. O público é o pressuposto para a realização da individualidade humana singular. Algo, hoje, completamente inviável, ainda mais quando a tendência hegemônica é a de privatização dos espaços da vida social.

É nesse horizonte que a ontologia da diversidade humana é substituída pela ideologia da diversidade cultural, que tem como lema a valorização da diferença. Há, indubitavelmente, uma perda substantiva de significado e de referenciais em termos de critérios parametradores às ações humanas, dado que os indivíduos sociais não mais conseguem enxergar as mediações ontologicamente (histórico-sociais) existentes entre eles e o gênero humano, e suas escolhas voltam-se a atender a satisfação de seus desejos e pulsões individuais, que redundam no mais completo individualismo e monismo que contribuem para o crescente isolamento entre si. De modo que

a solidão é, nestas circunstâncias, quase um pré-requisito para a elevação afetiva e pessoal do indivíduo para além da banalização cotidiana. A fragmentação está instalada no próprio seio das 
individualidades: sua identidade se afirma privadamente, na reclusão, no isolamento; sua vida coletiva, aquelas relações que conectam a pessoa ao gênero humano, não servem de mediação para a expressão do que cada um de nós é enquanto pessoa humana. (LESSA, 2004, p. 7)

As ideias, de uma perspectiva ontológica e lukacsiana, são uma determinação reflexiva das contradições da vida social e das condições materiais de existência e de reprodução social, portanto, não se trata da busca pelo conhecimento falso ou verdadeiro, de afirmar que uma ideia é falsa ou verdadeira, como é o caso da perspectiva gnoseológica/epistemológica, mas sim de verificar como, objetivamente, elas plenificam de sentido a vida humana, ou seja, como uma ideia se torna ideologia.

Por isso Marx dizia que "não se julga o que um indivíduo é a partir do julgamento que ele se faz de si mesmo" (1978, p. 130), e as ideologias, portanto, são engendradas dessas contradições e condições, resultando numa determinada visão de mundo, que orienta o modo como os indivíduos se relacionam com ele e entre si, jogando um papel essencial na escolha entre alternativas porque, ainda que essas escolhas sejam limitadas e delimitadas pela condição de classe desses mesmos indivíduos, pela forma como se inserem e pelo lugar que ocupam nas relações sociais e de produção capitalistas, ainda assim, justificam e dão sentido ao modo como vivem suas vidas, e esta é a função social da ideologia, num sentido amplo, como explicita Vaisman (1989, p. 399-421) ao expor o pensamento de Lukács, pois

do ponto de vista ontológico, ideologia e existência social (em qualquer nível de desenvolvimento) são realidades inseparáveis. Ou seja, onde quer se manifeste o ser social há problemas a resolver e respostas que visam a soluções destes; é precisamente nesse processo que o fenômeno ideológico é gerado e tem seu campo de operações. (VAISMAN, 1989, p. 419)

Já o sentido restrito da ideologia corresponde à sociabilidade fundada e organizada através da propriedade privada, do capital, do trabalho assalariado, que gera a sociedade de classes e da luta de classes e, portanto, uma ideologia de classe, de como a classe capitalista e a classe trabalhadora leem e atuam no mundo, justificando seu ser, agir, sentir, pensar, fazer, interagir. Assim, explicitando a caracterização da ideologia no seu sentido restrito, conforme a perspectiva lukacsiana, Vaisman (1989, p. 419 e 420) esclarece que, 
na medida em que o conflito social passa a fazer parte da realidade dos homens, apresentando-se como problemática vital, a ideologia volta-se à resolução dos problemas agora transpassados por este conflito básico, ou seja, a ideologia passa a se manifestar como um instrumento ideal através do qual os homens e as classes se engajam nas lutas sociais, em diversos planos e níveis. (...) $\mathrm{Na}$ acepção restrita de ideologia, portanto, ideologia é instrumento de conscientização e de luta social que caracteriza pelo menos aquelas (sociedades) da pré-história da humanidade, ou seja, aquelas sociedades divididas em classes sociais antagônicas, que por meio da ideologia conscientizam e enfrentam conflitos derivados de seus interesses contrapostos.

É assim que podemos entender porque a ideia da diversidade cultural, da valorização da diferença, dos particularismos e das ações locais em detrimento do macrossocial ganham cada vez mais terreno, mais corações e mentes, contribuindo para o processo de desontologização do real, da história e do ser social, fortalecendo a ideologia dos intelectuais orgânicos do capital, como os pósmodernistas e pós-estruturalistas (ainda que se intitulem críticos) e suas explicações pontuais, discursivas e anti-causais, como demonstrado. Como assevera Wood (1999, p. 19 e 20),

Para membros da esquerda, e em especial para a geração mais jovem de intelectuais e estudantes, a maior atração do pósmodernismo é sua aparente abertura, em contraste com os alegados 'fechamentos' de um sistema 'totalizante' como o marxismo. Essa alegação de abertura, no entanto, é na maior parte falsa. O problema não é apenas que o pós-modernismo represente um tipo ineficaz de pluralismo que abala suas próprias fundações. Nem é simplesmente um ecletismo acrítico mas inócuo. Há em jogo algo mais sério. A 'abertura' dos conhecimentos fragmentários do pós-modernismo e sua ênfase na 'diferença' são compradas ao preço de fechamentos muito mais fundamentais. O pós-modernismo é, a sua maneira negativa, um sistema inexoravelmente 'totalizante', que impede uma gama mais vasta de pensamento crítico e de política libertadora - e seus fechamentos são finais e decisivos. Seus pressupostos epistemológicos tornam-se inacessíveis à crítica, tão imune quanto o mais rígido tipo de dogma (como criticar um conjunto de ideias que, a priori, exclui o próprio emprego do argumento 'racional'?). E impede - não apenas ao rejeitar dogmaticamente, mas também por tornar impossível - uma compreensão sistemática de nosso momento histórico, uma crítica geral ao capitalismo e, praticamente, a toda e qualquer ação política eficaz. 
Vemos, portanto, o quanto a ideologia da diversidade cultural - como suas variações: pluralismo cultural, multiculturalismo - dos pós-modernistas e pósestruturalistas serve ao processo de conciliação e resignação com a atual condição de alienação humana, sendo muitíssimo eficaz em impedir a unificação e articulação das lutas dos diferentes movimentos e segmentos sociais, particularizando-as, fragmentando-as, pulverizando-as e isolando-as, neutralizando sua força política-social, obliterando e desterrando a base de sua unidade, que é a condição material e existencial desses indivíduos, ou seja, sua condição de classe, uma luta, essencialmente, de alma social. A fim de garantir o controle sobre o social e suas ações, fazendo a manutenção da paz e da ordem, não há melhor arma do que ideologias persuasivas, com reconhecimento científico para enfraquecer as possíveis vozes resistentes da contra-hegemonia, desfocando do problema central e de suas contradições: as relações sociais e de produção capitalistas e a luta de classes.

\section{Referências Bibliográficas}

CHASIN, J. Marx - Estatuto Ontológico e Resolução Metodológica. Posfácio à obra: Pensando com Marx - Uma Leitura Crítica Comentada de O Capital. TEIXEIRA, Francisco José Soares. São Paulo: Ensaio, 1995, p.403.

DELLA FONTE, Sandra Soares. Fundamentos teóricos da pedagogia históricocrítica. In: MARSIGLIA, Ana Carolina Galvão (Org.). Pedagogia histórico-crítica: 30 anos. Campinas, SP: Autores Associados, 2011. (Coleção memória da educação)

FOSTER, John Bellamy. Posfácio - Em defesa da história. In: WOOD, Ellen Meiksins; FOSTER, John Bellamy (Orgs.). Em defesa da história: marxismo e pósmodernismo. Trad. Ruy Jungman. Rio de Janeiro: Jorge Zahar Ed., 1999.

LENIN, Vladimir I. Materialismo e empiriocriticismo. Moscou, Edições Progresso; Lisboa: Avante, 1982.

LESSA, Sérgio. Identidade e Individuação. In: Revista Katalysis, UFSC, v.7, n. 2, p. 147-157, 2004.

LESSA, Sérgio. A Ontologia de Lukács. Maceió: Edufal, 1996.

MALIK, Kenan. O espelho da raça: o pós-modernismo e a louvação da diferença. In: WOOD, Ellen Meiksins; FOSTER, John Bellamy (Orgs.). Em defesa da história: marxismo e pós-modernismo. Trad. Ruy Jungman. Rio de Janeiro: Jorge Zahar Ed., 1999. 
MARX, Karl; ENGELS, Friedrich. A Ideologia Alemã: crítica da mais recente filosofia alemã em seus representantes Feuerbach, B. Bauer e Stirner, e do socialismo alemão em seus deferentes profetas (1845-1846). Supervisão editorial, Leandro Konder; tradução, Rubens Enderle, Nélio Schneider, Luciano Cavini Martorano. São Paulo: Boitempo, 2007.

MARX, Karl. Manuscritos econômico-filosóficos e outros textos escolhidos. 2ed. São Paulo: Abril Cultural, 1978. (Os Pensadores)

MARX, Karl. Teses sobre Feuerbach. In: MARX, Karl; ENGELS, Friedrich. Obras Escolhidas. v. 3. Rio de Janeiro: Editorial Vitória Ltda, s/d.

MÉSZÁROS, István. Marx: A Teoria da Alienação. Rio de Janeiro: Zahar, 1988.

VAISMAN, Ester. A ideologia e sua determinação ontológica. In: Revista Ensaio, 17/18. São Paulo: Ensaio, 1989. (Filosofia/Política/Ciência da história)

WOOD, Ellen Meiksins. O que é a agenda "pós-moderna"? In: WOOD, Ellen Meiksins; FOSTER, John Bellamy (Orgs.). Em defesa da história: marxismo e pósmodernismo. Trad. Ruy Jungman. Rio de Janeiro: Jorge Zahar Ed., 1999.

Recebido em: 21 de agosto de 2017 Aprovado em: 26 de outubro de 2017 Publicado em: 5 de dezembro de 2017 